\title{
Mental Space Theory and Misunderstanding
}

\author{
Hui Liu \\ School of Foreign Languages, Beijing Forestry University \\ 35 Qinghua East Road, Haidian District, Beijing 100083, China \\ Tel: 86-150-11363961 E-mail: liuhui1982@126.com \\ Yueqin Gao \\ School of Foreign Languages, Beijing Forestry University \\ 35 Qinghua East Road, Haidian District, Beijing 100083, China \\ Tel: 86-136-71043825Ｅ-mail: yueqingao@yahoo.com
}

\begin{abstract}
This essay attempts to conduct an explanatory research on MIS within the framework of mental space theory to demonstrate the cognitive operating process of MIS in people's social interaction and explore the deep causes lying behind the phenomenon. By text analysis, the author elaborates on the generating process of MIS, thus tracing cognitive causes that lead to the generation of MIS.
\end{abstract}

Keywords: Mental space theory, Conceptual blending, Misunderstanding (MIS), Cognitive causes

\section{Literature review on the studies of mental space theory and misunderstanding}

Mental space theory was initiated by Gilles Fauconnier in 1985 with the publication of his book Mental Spaces: Aspects of Meaning Construction in Natural Language. In the following decades, the theory got further development by the other two pieces of his works, Mappings in Thought and Language and The Way We Think: Conceptual Blending and the Mind's Hidden Complexities.

Mental space theory focuses on people's psychological operation in meaning construction. According to the theory, meaning construction refers to "the high-level, complex mental operations that apply within and across domains when we think, act, or communicate" (Fauconnier 1997, p.1). When people use language to communicate with each other, they constantly construct such domains triggered by linguistic information and current contexts, by which people accomplish meaning construction and realize mutual communication. These domains are called spaces by Fauconnier, which refers to "small conceptual packets constructed as we think and talk, for purposes of local understanding and action" (Fauconnier \& Turner 2002, p.40).

A further development of mental space theory is the theory of conceptual integration, or blending. It is a theoretical framework for exploring information integration that underlies the construction of meaning and thus provides a new perspective for meaning construction. The theory can be presented by a full four-space blend mode looks like Fig. 1.1.

Insert Figure 1.1 Here

In the typical mode presented in Fig. 1.1, four spaces are involved, namely the two input spaces (I1 and I2), the generic space, and the blended space. Selective cross-space mapping occurs between I1 and I2, and their common abstract structures are projected into the third space - the generic space. The two inputs are then partially projected onto the fourth space - the blended space and the emergent structure is formed through composition, completion and elaboration, which are represented by the square in the diagram. The diagram indicates that "when counterparts are projected into the blend, they may be fused into a single element or projected separately. An additional possibility, not reflected in the diagram, is that "one of the counterparts is projected but not the other" (Fauconnier 1997, pp.149-151)

As a comparatively new theory concerning people's cognitive activities in meaning construction, it has drawn much attention from cognitive linguists abroad, including Coulson \& Oakley (2005, pp.1510-1536); Brandt (2005, pp.1578-1594); and Harder (2005, pp.1636-1652), etc.

Since the mental space theory first introduced to China by Wang Shaohua (2000, pp.21-26), an increasing number of scholars began to turn their attention to this theory, among them, representatives are Liu Yuhong (2002, pp.34-41); and Sun Ya (2001, p.16-19), etc. 
According to Bazzanella and Damiano (1996b, pp.175-188), misunderstanding (MIS) is the mismatch between the speaker's intended meaning and the interlocutor's interpretation of a given turn. In Milroy (1986), MIS is a simple disparity between the speaker's and the hearer's semantic analysis of a given utterance. Stratos (1981) refers MIS to the failure of a hearer to understand a speaker's utterance, i.e. the hearer's failure to recognize what the speaker intends to convey. Thomas (1983, p.91-112) believes that MIS arises from an inability on the part of the hearer to recognize the force of the speaker's utterance. Therefore, we can understand MIS as a pragmatic phenomenon involving the hearer's unintentional and incorrect interpretation which is not intended by the speaker in social interaction.

As a form of unsuccessful communication, MIS has been receiving extensive attention from linguists, sociologists, psychologists, and researchers of communication. (Austin 1962; Thomas 1983; Miller 1994; Fabian 1997; Young 1999; Yus 1998, 1999, etc.).

In China, most comprehensive studies specialized in MIS are He Ziran (1988), Xiong Xueliang (1995), etc.

\section{Research Design}

\subsection{Research Hypothesis}

We claim that when interlocutors carry out meaning construction as discourse proceeding, they constantly construct various mental spaces related to the current context. Basing on the spaces, they unfold complex cognitive operations spontaneously. In a case where MIS emerges, the information, linguistic or non-linguistic, provided by the speaker provides an input space $\left(I_{I}\right)$, or utterance space, for interlocutors' meaning construction under conceptual blending framework. Basing on the space, both the speaker and the hearer unconsciously carry out a series of psychological operation and respectively establish some related spaces triggered by the utterance space. These spaces function as another input space $\left(I_{2}\right)$ in their cognitive operation. After a series of logic running basing on the two input spaces, the content of the two inputs are blended and emergent structures are formed separately in the interlocutors' minds. Consequently, the speaker develops the meaning he/she intends to convey, and the hearer infers the implied meaning of the speaker's utterance. If the meaning produced during the hearer's cognitive operation is different from that developed by the speaker, MIS will emerge. Therefore, we assume that the two major origins of MIS can be traced under conceptual integration mode: Opacity of information contained in input space 1 provided by the speaker; and difference of the content of the two input spaces constructed by the speaker and the hearer respectively.

\subsection{Research Data}

The data in the present study are collected in three ways. Firstly, some examples of MIS in the present study are found by chance in conversations happening between close friends. They are naturally generated in everyday communication and are consequently authentic in nature. Secondly, plays and novels provide a reliable source of simulated MIS examples. Finally, some examples from other researchers' studies are analyzed.

\subsection{Research Analysis}

In a discourse, the speaker's expressions, either linguistic or non-linguistic, set up a space containing various elements and relations holding among them basing on which the hearer can construct new related spaces and conduct cognitive operation so as to get the meaning intended by the speaker. In the conceptual blending mode, it plays its role as input space $1\left(I_{l}\right)$. It works just like a lighthouse to guide the hearer to carry out meaning construction in the way he/she expects. However, if the guideline is vague, or opaque, in itself, it will be definitely unable to give the exact direction for the hearer's cognitive operation, which will be very possible to result in MIS. Opacity of information contained in $I_{l}$ in the conceptual integration network is an important origin of MIS. Here is an example:

(1) Daiyu: Tell me, are you just painting the Garden or us as well?

Xichun: The idea at first was just the Garden. But yesterday the old lady objected that that would look like an architect's drawing. She told me to put everybody in, just as in a family outing. I'm no good at the details of buildings or at painting people either, but I can't very well back out now. A fine fix I'm in.

Daiyu: People are easy. But can you paint insects?

* Li Wan: You are talking nonsense again. What insects does this painting need? A bird or two, perhaps, would be appropriate.

Daiyu: We can dispense with other insects. But the painting will have no point without yesterday's Old Mother Locust. 
In this case, Daiyu makes fun of Liu Laolao by calling her "old mother locust" (Muhuangchong). Therefore, by saying "old mother locust", she is actually referring to Liu Laolao. The concrete cognitive operation goes on like this:

\section{Insert Figure 2.1 Here}

While on Li Wan's part, basing on Daiyu's expression (I1) as well as the background knowledge stored in her mind, she sets up a new space, namely $\mathrm{I} 2$, which contains elements $b, c, d$, $e$, and $f$, as shown in Fig. 2.2:

\section{Insert Figure 2.2 Here}

The common structure $g$ shared by elements $a$ and $f$ is projected into the generic space, which determines the cross-space mapping of the two. The two are projected onto the blend and are fused. Basing on her background knowledge, elements $b, c, d$ and $e$ are projected into the blended space as well. After a series of logic running in the blend, the emergent structure is formed: "Xichun will not only paint gardens, people and also old mother locust". That is how Li Wan misunderstands Daiyu's words. The deep reason is that when Daiyu expresses her opinion, she resorts to the metaphorical rather than the explicit expression, which does not provide clear information for Li Wan to establish corresponding mental spaces.

Generally speaking, the influence of speakers' information opacity on the hearers' meaning construction works in three ways: Opacity of linguistic information provided by the speaker; unintelligibility of contextual information to the hearer; and the combined effect of opaque linguistic information and unintelligible contextual information. The reason is that, though linguistic expressions are the major tool carrying our communication, context is still an element to be reckoned with, because we always operate meaning construction in contexts. Therefore, opacity of the speaker's information in a discourse may lies in either linguistic expressions or contextual information, or both sometimes.

As mentioned above, language users always operate in contexts. That "allows us to use our linguistic resources to the utmost without having to spell out all the tedious details every time we use a particular construction" (Jacob 2001, p.45). The economical use of language may save time and energy for mutual communication on the one hand, but also leave the hearers confused about the speakers' actual intention on some occasions on the other, thus leading them to operate meaning construction in different ways and causing MIS between them. Look at the following cases:

(2) Ben, Ross's son, is learning to ride a bike in a park-

Phoebe: I never had a bike of my own. (1)

Ross: What? (2)

Phoebe: We didn't have a lot of money, you know. But the girl across the street had the best bike... (3)

Monica: Did the girl ever let you ride it? (4)

Phoebe: No. But the girl gave me the box that it came in. It had a picture of the bike on the front. So I would sit on it and my stepdad would drag me around the backyard. (5)

Ross: (pitifully) That is so unfair. (6)

Phoebe: Not really. I got to drag him around, too. (7)

(Friends)

The MIS in this example locates in sentence (7). On hearing Phoebe's miserable experience in her childhood, Ross feels very sorry about that by saying "That is so unfair" sympathetically, which actually means "That is so unfair for you to suffer such pitiful childhood". In diagrammatical form, all this will be expressed in the kind of representation given in Fig. 2.3.

Ross' cognitive operation:

Insert Figure 2.3 Here

Ross' utterance (sentence (6) opens up a basic space which works as input $I_{l}$ for his conceptual blending operation. It contains a subject $a$ (represented by the pronoun "that"), property of "unfair" (b), and "is" relation existing between $a$ and $b$ (labeled by $c$ in the diagram). The space is established based on another space-the past space, which has already come into being in Ross' mind by virtue of Phoebe's previous narration. It works as $I_{2}$ in the conceptual blending network. The past space has two elements, $d$ and $e$, which are actually smaller spaces entailed by the past space. The common abstract structure shared by $a$ in the basic space and $d$, $e$ in the past space is projected onto $a^{\prime}$ in the generic space, which in turn maps onto $a$ and $d$, $e$ separately. $a$ ', therefore, determines the 
cross-mapping between $a$ and $d, e$ separately in the two input spaces. Then $a$ in the basic space and $d, e$ in the past space are projected onto the blend and are fused. Element $b$ and relation $c$ in $I_{l}$ are projected into the blend as well. In the blend, Ross unfolds a series of abstract logic operation and gets the emergent structure, i. e., the implied meaning of his utterance: That is so unfair for you to have such miserable past.

However, Phoebe takes Ross' sympathetic expression as a kind of blaming. Putting it diagrammatically, Ross' linguistic expression (sentence (6) opens a space (basic space- $I_{l}$ ) for her, as represented in Fig.2.4.

Phoebe's cognitive operation:

Insert Figure 2.4 Here

Basing on the current context and her background knowledge, Phoebe sets up a relevant space - the past space $\left(I_{2}\right)$, and adds elements $d, e$, and relation $f$ into it. Because $d, e$, and $f$ in the past space form an integrated action together which is "unfair" in nature, they find their counterpart $a$ in $I_{l}$. Their common structure is projected onto $a$ ', "something with the property of "unfair", in the generic space, and the cross-space mapping between them occurs as well. Elements $a, d$, and $e$, and relation $f$ from the input spaces are projected into the blend, and are fused. Element $b$ and relation $c$ in $I_{l}$ are also projected into the blend. In the blended space, $d, e, f$, and $a$ are composed which represents the unfair fact that $H$ enjoys being dragged by her step-dad instead of doing the same thing in turn, which entails the emergent structure: That is so unfair for you to have your step-dad drag you around. No wonder that she replies Ross by declaring "I got to drag him around, too" seriously.

The opacity of the information in $I_{l}$ locates in the unspecified subject of Ross' utterance. The description given in $I_{l}$ is referentially transparent from the speaker's point of view, while it is opaque from the point of view of the hearer (Phoebe). That is where many cases of MIS generate in discourse.

(3) Rachel's father suffered from a heart-attack. Rachel went back to her room with Ross-

Ross: Are you ok? (1)

Rachel: Yeah.

Ross: "Yeah" to a rough day, huh?

Rachel: Yeah. It's just so weird seeing him like that, you know? I mean, he's a doctor. You don't expect doctors to get sick. (4)

Ross: But we do. (5)

\section{(Friends)}

The MIS in this example locates in sentence (5). It is known to all that the word "doctor" can be interpreted in two ways: "A person whose profession is to treat sick people", and "a person holding one of the highest degrees given by a university, such as a PhD". Rachel's father is a doctor in the former sense, while Ross is a $\mathrm{PhD}$ whose profession is paleontology. Here we take Rachel as the speaker $(S)$ and Ross as the hearer $(H)$. $S^{\prime}$ utterance "You don't expect doctors to get sick" opens a space based on which both $S$ and $H$ conduct a series of cognitive operation:

$S$ ' cognitive operation:

Insert Figure 2.5 Here

While saying sentence (4), a relevant space has been built by $S$ basing on her background knowledge that her father is a doctor whose job is to treat sick people. There are two elements $d$ and $e$ in it, as shown in Fig. 2.5. Element $a$ in the utterance space $\left(I_{I}\right)$ and elements $d$ and $e$ in $S$ " newly built space share the common structure: "Person with a profession of treating sick people", which is projected into the generic space. Because of that, cross-space mapping between them occurs. The three elements mentioned above are projected into the blend and are fused consequently. Relations $b$ and $c$ in $I_{l}$ are projected into the blend as well. Elements and relations in the blend are then elaborated and the emergent structure is formed which actually is implied in $S$ ' utterance: It is un-expectable to see my father get sick whose job is to treat sick people.

$H$ 's cognitive operation:

Insert Figure 2.6 Here

However, the way of meaning construction conducted by $H$ is different from that expected by $S$. $S$ ' linguistic expression provides an input space $\left(I_{I}\right)$ for $H$ 's cognitive operation which contains element $a$ and relations $b$ and $c$. Spontaneously, his background knowledge about the topic is activated at the same time. Basing on that, he sets up a space $\left(I_{2}\right)$ related to $S$ ' language space, and there are four elements, $d, e, f$, and $g$, in it. The two spaces function as 
two input spaces in the network of his cognitive operation, as shown in Fig.2.6. Basing on the linguistic information provided by $S$, the contextual information, and his background knowledge, $H$ finds counterparts of $a$ in $I_{l}$ in the new relevant space $\left(I_{2}\right)$, which include not only $S$ ' father, the person whose profession is treating sick people, but also he himself as a $\mathrm{PhD}$. Their common structure, $a$, is projected into the generic space, which defines the cross-space mapping between them. Then $a$ in $I_{1}$ and $d, e, f, g$ in $I_{2}$ are all projected into the blend and are fused. Relations $b$ and $c$ are also projected into the blend separately. Elements and relations in the blend undergo a series of logic running through which the emergent structure is produced: Though we doctors are unexpected to get sick, we actually do sometimes.

Comparing the cognitive operations of $\mathrm{S}$ and $\mathrm{H}$, it is obvious that the cause of the MIS in this example lies in the ambiguous linguistic expression "doctor" which is a piece of information contained in $I_{l}$ provided by the speaker. Ambiguity is a common form of linguistic information opacity in $I_{2}$.

(4) Monica is sitting in the couch in her apartment. Chandler opened the door and walked in-

Chandler: You know I was thinking, what if I uh, unpack here?

* Monica: Then all your stuff would be here.

Chandler: Well, what if all my stuff was here?

* Monica: Then you'd be going back and forth all the time. I mean it doesn't make any sense.

Chandler: Okay. What if we lived together and you understand what I'm saying?

\section{(Friends)}

Chandler and Monica are seeing each other. They get along very well. Chandler wants to move into Monica's apartment and live together with her. So he makes a reserved suggestion by asking "what if I unpack here". The sentence opens a space (utterance space) here with an unpack relation in it (labeled by $a$ in the diagram below). At the same time, another space about the action of "moving" (moving space) has been prompted, which contains all the elements and structures related to the "moving" process.

Insert Figure 2.7 Here

Relation $a$ in the utterance space is mapped onto the whole frame of the "moving" action, which entails that the entire "moving" thing is represented by only one of its components - the action of unpacking. The cross-space mapping reveals the implied meaning of Chandler: What if I move in and live together with you?

Obviously, Monica does not carry out such cognitive operation, and consequently fails to understand the real intention of Chandler' utterance. In this case, the opacity of information provided by the speaker locates in the implicitness of the speaker's linguistic expression.

Language users always operate in contexts. Therefore, the context looms large, and has to be taken into account whenever we formulate our thoughts about language. According to Jacob (2001), context is a dynamic, not a static concept. It is to be understood as the continually changing surroundings, which enable the participants in the communication process to interact, and in which the linguistic expressions of their interaction become intelligible. However, if the contextual information in the space provided by the speaker is unintelligible to the hearer, it would become very possible for the hearer to interpret the speaker's utterance in a wrong way and end up with MIS.

(5) A is holding a watch, intending to correct the time. B is writing a paper.

A: What's the time now?

* B: It's after eight.

A: I know it's after eight, but what's the exact time?

B: Oh...It's 8:05.

In this example, $\mathrm{A}(\mathrm{S})$ wants to correct the time. By asking $\mathrm{B}(\mathrm{H})$ the time with the watch in his hand, $A$ intends the exact time actually, and $B$ is supposed to carry out meaning construction like this:

\section{Insert Figure 2.8 Here}

The expected emergent structure should be: $A$ intends to correct the time with the watch in his hand, and I am supposed to tell him the exact time. However, as $H$ is writing a paper at the moment, the contextual information, the gesture of holding the watch, provided by $A$ failed to make itself explicit to $H$. Therefore, the element $a$ in $I_{l}$ offered by $S$ is unintelligible to $H$. The actual process of $H$ 's meaning construction proceeds like this:

Insert Figure 2.9 Here 
The space offered by $S$ contains element $a$ and relation $b$. As the contextual information-the gesture of holding the watch is not intelligible to $H$, the element is not included in the utterance space $\left(I_{I}\right)$ provided by $S$ on $H$ 's side. Basing on $I_{1}$ provided by $S, H$ sets up a space $\left(I_{2}\right)$ and adds two elements into it: $c$ and $d$. Regarding the social convention that in most cases, a vague answer is enough when one is asked for the time, he maps $a$ onto $c$ ('rough time') instead of $d$ ('exact time'). Their common structure $a$ ' is projected into the generic space. Then $a$ and $c$ are projected into the blend and are fused. $b$ is also projected into it. In the blend, elements $a$ and $c$ are composed which implies that the vague time is inquired by $S$. Combined with the action of inquiring and relevant social conventions activated, $H$ unfolds a series of logic running subconsciously. As a result, elements and relations in the blend are completed and elaborated and the emergent structure is formed: $A$ is asking the time, and a rough answer is enough on most occasions. The MIS in this case lies in the unintelligibility of contextual information in $I_{l}$ provided by the speaker.

Both opaque linguistic information and unintelligible contextual information can result in the generation of MIS in discourse. But some cases of MIS are caused by the combined action of the two factors.

(6) Rachel is having a job interview at Ralph Lauren. Zelner is the interviewer-

Zelner: Hi Rachel! Come on in!

Rachel: Hi!

Zelner: It's really nice to see you again.

Rachal: Thank you!

Zelner: Oh Rachel, uhh-(noticing Rachel gets ink on her lip, points at his own to give her a hint)

Rachel: What?

Zelner: Just ah-(leans forward)

Rachel: Excuse me? (steps backward)

Zelner: Here let me- (steps up, intending to help her get rid of the stain)

* Rachel: (stops him, getting furious) Wh-whoa! All right. Okay-okay, I see. I see what's going on here. Now listen, look-look, I am sorry if I have given you the wrong impression, but I am not some hussy who will just sleep around to get ahead! Now even though I ...

\section{Zelner: No I-}

* Rachel: Hey-hey-hey, even though I kissed you, that- that does not give you the right to demand sex from me. I do not want this job that bad. Good day, sir. (leaves the room angrily)

\section{(Friends)}

In the previous interview, Rachel misread the intention of Zelner's action of leaning forward to open the door and kissed him mistakenly. She was really awkward and upset about that. On getting informed about the second interview, she doubted that Zelner gave her the chance only because she behaved like a "hussy" last time and he wanted to take advantage of her. Therefore, she is very defensive in the interview.

In the scene presented above, Zelner notices the ink stain on Rachel's lip. In order to be polite and avoid Rachel's awkwardness, he does not put it straightforwardly. Rather, he makes a series of hints. However, his kind intention is totally misunderstood by Rachel. To explain the cognitive operation of Rachel diagrammatically:

Insert Figure 2.10 Here

Zelner's series of implicit linguistic expressions and actions provide the input space $1\left(I_{1}\right)$ for Rachel's meaning construction of his implicit expressions. Basing on $I_{l}$ and her background knowledge about the former awkward accident, Rachel establishes a relevant space $\left(I_{2}\right)$ with elements $f, g$, and $h$ in it. The common structures shared by $a$ and $f, c$ and $g$, and $d, e$ and $h$ are projected onto $a^{\prime}, c^{\prime}$ and $h^{\prime}$ in the generic space respectively, which define the cross-space mapping between them respectively. Elements $a$ and $f$ are projected into the blend and are fused into one element. The composed element indicates that the opposite part in this conversation is the person she mistakenly kissed last time who might be liable to take her as a "hussy". Other elements and relations are projected into the blend as well. Through composition, completion, and elaboration, she relates Zelner's action of pointing at his lip with the hint of the previous kiss, and takes his movements of leaning forward and stepping up as a sign of violation, hence developing the emergent structure: He is doing something to remind me of kissing him last time and wants to take advantage of me. That is why Rachel gets so furious and delivers so long a speech with such strong emotion. The MIS in this case is resulted mainly from the implicit linguistic expressions and the unintelligible contextual 
information Zelner, the speaker, conveys to Rachel, the hearer. What allows no neglect concerning the causes of MIS is communicators' psychological factor. In this discourse, Rachel's MIS about Zelner's intention can also be attributed to her self-defensive mentality. This factor will be discussed in detail later.

Conceptual blending theory is a development of mental space theory intended to account for cases in which the content of two or more mental spaces are combined to yield novel inferences. In the conceptual integration network, the blended space inherits partial structure from two or more different input spaces. In cases where MIS occurs, the speaker's linguistic and/or non-linguistic expression opens a space which functions as input space $1\left(I_{1}\right)$ for the two parties' meaning construction. Then it prompts the both sides to set up relevant mental spaces which function as input space $2\left(I_{2}\right)$ in their separate cognitive operation. In previous discussion, many cases of MIS are caused by opacity of information in $I_{l}$. However, the information offered by speakers is sometimes transparent to both sides, and MIS generates only because the contents of the two input spaces constructed by the speaker and the hearer are different. That may be caused by various factors, such as discrepancy of background knowledge activated by the speaker and the hearer in conceptual integration, cognitive structure difference of the speaker and the hearer, and psychological factor. The three factors will be studied one by one.

(7) A: Let me have a rest. I'm already knocked up. (1)

* B: My heartiest congratulation to you! (2)

A: Why do you say that? (3)

B: Why shouldn't I? You're in a family way. (4)

(Ke Jinsuan 1984)

Insert Figure 2.11 Here

The British's utterance (sentence (1) stimulates the American to set up a relevant space based on his background knowledge and the current context, as shown in Fig. 2.11. The American $(B)$ consequently activates his background knowledge about "being knocked up" and finds $d$, the counterpart of $b$ in the utterance space $\left(I_{l}\right)$ provided by the British $(A)$, and adds it into his mental space $\left(I_{2}\right)$ currently built. Element $a$ in $I_{1}$ is identified by element $c$ in $I_{2}$. While in $A$ 's background knowledge, "being knocked up" actually refers to "being exhausted". Different content of input spaces established by $A$ and $B$ will definitely lead to different emergent structures which inherit structures from inputs. The MIS in this example is rooted in the discrepancy of background knowledge of the communication participants, which is a reflection of cultural difference.

Apart from background knowledge difference of the communicators', discrepancy in cognitive structure of meaning construction conductors is another important cause leading to MIS. About the same issue, different people may think in different ways. That may be attributed to the variety of information processing ability, cognitive proficiency, or cognitive context capturing ability of meaning constructors.

(8) One day, the little boy Linus wants to play with Violet, a girl who is older than him. So he goes to Violet's house-

Linus: Do you want to play with me, Violet? (1)

Violet: You are younger than me. (shuts the door) (2)

* Linus: (puzzled) She didn't answer my question. (3)

Violet rejects Linus' invitation by saying "You are younger than me" (sentence (2)). Here we take Violet as the speaker (S) and Linus as the hearer $(H)$. At the moment, $\mathrm{S}$ has already unconsciously activated her background knowledge that "among children, big girls don't play with little boys", based on which a mental space is set up, as denoted in Fig. 2.12.

Insert Figure 2.12 Here

Element $a$ in $I_{1}$ is mapped onto element $d$ in $I_{2}$ because of the common structure (Violet belongs to the category of big girls) they share, and that is projected into the generic space. Consequently, cross-space mapping occurs between $a$ and $d$. The same thing happens to $b$ and $e$ (Linus belongs to the category of little boys). The structure " $d$ don't play with $e$ " in $I_{2}$ and the structure " $b$ invites $a$ " in $I_{l}$ are projected into the blend. Elements $a$ and $d$ are projected into the blend and are fused which indicates that "Viloet is a big girl". Elements $b$ and $e$ are also fused together in the blend, indicating that "Linus is a little boy. Basing on the above cognitive operation, $S$ integrates relation $c$ in $I_{I}$ and structure $f$ in $I_{2}$. $S$ then elaborates the elements and structures in the blend and gets the emergent structure: Big girls don't play with little boys. You are younger than me, so I don't play with you. 
But $H$ lacks the necessary background knowledge, and is weaker in carrying out relevant cognitive constructions. He is too young to get the implied meaning of $S^{\prime}$ utterance (sentence (2)). Therefore, he fails to understand $S^{\prime}$ implied rejection and wonders why didn't the girl answer his question. Obviously, the MIS in this example is resulted from the communicators' cognitive structure discrepancy.

Another example is excerpted from the play Forrest Gump:

(9) Gump and Bubba met Lieutenant Dan for the first time-

Gump and Bubba: Morning, sir! (saluting Dan) (1)

Dan: Get your hands down... Where are you boys from in the world? (2)

Gump and Bubba: Alabama, sir! (3)

Dan: You twins? (4)

* Gump: No, we are not relatives, sir. (5)

\section{(Forrest Gump)}

Gump, the leading character in the movie, is mentally challenged and is less proficient in information processing than normal people. The cognitive structure discrepancy of him and others often lead to the generation of MIS.

In the scene presented above, Gump and his friend Bubba answer Lieutenant Dan's questions in one voice in a mettlesome manner. They are used to behaving in this way due to their former military experience. However, this kind of behavior is strange and funny to Dan, the officer who meets them for the first time. Consequently, he expresses his curiosity by asking "You twins?". In this case of MIS, we take Dan as the speaker $(S)$ and Gump the hearer $(H)$. $S$ ' utterance (sentence (4)) opens up a space (utterance space) for mutual cognitive operation. In this space, one important element is "twins". With the utterance of the question (sentence (4)), $S$ is spontaneously prompted to open up another space related to the utterance space, which involves two corresponding counterparts, or two implications, of the element "twins": "Two children born to the same mother at the same time" (b); and "two things which are closely connected or very like each other" (c), as shown in Fig. 2.13.

\section{Insert Figure 2.13 Here}

Since Dan is quite clear that Gump and Bubba can not be real twins (Gump is white while Bubba is Black), he finds the counterpart of element $a$ in the space he newly established - "two things which are closely connected or very like each other". Basing on this kind of cognitive operation, he conveys his implied meaning: Why do you behave in such a strange manner?

However, Gump, the hearer, fails to get Dan's intended meaning due to his different cognitive structure which contains only the basic implication of the word "twins". Naturally, he maps the element $a$ in the utterance space onto the basic meaning "two children born to the same mother at the same time" in the space he established basing on his background knowledge, hereby misunderstanding Dan's original intention with the ridiculous answer (sentence (5)). His cognitive operation is revealed in the following diagram:

\section{Insert Figure 2.14 Here}

The illustration of the above two MIS examples tells that MIS are inevitable in people's social interaction. One important reason is that people's cognitive structures are different one from another due to the influence of some factors like age, sex, character, intelligence level, and so on. Therefore, we cannot completely eliminate MIS in mutual communication. What we can do is to get a better idea about the law of language communication and try to avoid MIS as much as we can so as to keep smoother mutual communication.

In some cases, contents in the two input spaces built by the speaker and the hearer are different because the hearer is affected by psychological factors in the process of mental space construction. For example:

(10) Cao Cao and Chen Gong sat a good while. Suddenly behind the farmhouse they heard the sound of knives being whetted-

Cao: You know, Lv Boshe is not a close relative. There's something suspicious about his leaving. Let's look into this. (1)

The two men stole behind the cottage and overheard someone mumble-

Lv: Let's tie them up an' kill'm. (2)

Cao: I thought so. If we don't strike first, we'll be caught.

Cao Cao and Chen Gong entered at once and killed everyone, women and men, eight in all; only then did they see 
the trussed pig waiting to be slaughtered.

Chen: You were too suspicious. We've killed good folk. (4)

\section{(Luo Guanzhong The Three Kingdoms)}

The MIS locates in sentence (3). Cao Cao $(H)$ is known for his suspicious character in the story. On hearing $L v$ Boshe (S)' utterance, "Let's tie'm up an' kill'm." (Sentence (2)), he instinctively associates the object $S$ intends to kill with himself, as shown in Fig. 2.15.

Insert Figure 2.15 Here

In the utterance space $\left(I_{I}\right)$ provided by $S$, element $a$ could be anything that can be bound and killed which is probably a kind of animal in normal cases. However, the self-defensive psychology of $H$ drives him to associate "them" with himself, by which he infers that $S$ is planning to murder him. Because of his MIS about $S$ ' utterance, a tragedy occurred. Therefore, psychological factors are possible to affect communicators' meaning construction and lead to MIS between them.

One noteworthy point is that apart from psychological factor, the implicit expression "them" (in sentence (2)) may also attribute to $\mathrm{Cao}$ 's MIS about $L v$ 's utterance. People's cognitive operation is in fact a quite complicated process. It flows in an automatic and spontaneous manner. On most occasions, MIS is resulted from the combined action of several factors at the same time, which makes it hard to describe in a logic manner.

\section{Conclusion}

The present study proves that mental space theory can explain the causes of MIS by revealing the cognitive operating process of the MIS generation. The hypothesis is testified by an elaborated text analysis of various MIS examples collected from daily conversation, novels, plays, and other scholars' studies within the framework of mental space theory. The text analysis tells that mental space theory can be a new perspective to MIS study. Instead of taking MIS as a static language phenomenon, this study shows that we can study MIS through looking into people's dynamic cognitive operation as discourse proceeding. However, it is worth noting that people's cognitive operation in meaning construction flows in an automatic and spontaneous manner. In most cases, the cognitive causes of MIS do not work independently; or rather they are interwoven and function in an interactive and quite complicated way. Consequently, it would be very possible that people's psychological operation when MIS emerges could be influenced by the combined action of several factors at the same time, which makes it hard to describe in a logic manner.

\section{References}

Austin, J. L.(1962). How to Do Things with Words. Cambridge: Harvard University Press.

Bazzanella, C.\& R. Damiano. (1999b). Coherence and Misunderstanding in Everyday Conversations. In W. Bublita, U. Lenk, \& E. Ventola (Eds.), Coherence in Spoken and Written Discourse. Amsterdam: John Benjamins Publishing Company. pp. 175-188.

Brandt, P. A. (2005). Mental spaces and cognitive semantics: A critical comment. Journal of Pragmatics, 37, 1578-1594.

Coulson, S. \& Oakley, T. (2005). Blending and coded meaning: Literal and figurative meaning in cognitive semantics. Journal of Pragmatics, 37, 1510-1536.

Fauconnier, G. (1997). Mappings in Thought and Language. Cambridge: Cambridge University Press.

Fauconnier, G., \& M. Turner. (2002). The Way We Think: Conceptual Blending and the Mind's Hidden Complexities. New York: Basic Books.

Harder. P. (2005). Blending and polarization: Cognition under pressure. Journal of Pragmatics, 37, 1636-1652.

Jacob L. Mey. (2001). Pragmatics: An Introduction. Beijing: Foreign Language Teaching and Research Press.

Miller, L. (1994). Japanese and American meetings and what goes on before them: A case study of co-worker misunderstanding . Pragmatics, 4.

Stratos, G. A. (1981). Misunderstanding conversations between children and adults. Unpublished PhD Thesis at the University of California, Berkeley.

Thomas, J. (1983). Cross-cultural pragmatic failure. Applied Linguistics, 4, 91-112.

Thomas, J. (1995). Meaning in Interaction: an Introduction to Pragmatics. London: Longman.

Young, R. L. (1999).Understanding Misunderstandings. Austin: The University of Texas Press. 
Yus, F. (1999). Towards a pragmatic taxonomy of misunderstandings. Revista Canaria de Estudios Ingleses, 38, 217-239.

Yus, F. (1999). Misunderstandings and explicit/implicit communication. Pragmatics, 9, 487-517.

Ziran He. (1988). Pragmatics and English learning. Chang Sha: Hunan Education Publishing House

Yuhong Liu. (2002). Mental space theory and lexical ambiguities. Foreign Language Research, 108, 34-41.

Ya Sun. (2001). Mental space theory and translation. Shanghai Journal of Translators for Science and Technology, 4, 16-19.

Shaohua Wang. (2000). From blended space theory to the meaning construction of metaphors. Journal of Pla University of Foreign Languages, 6, 21-26.

Xueliang Xiong. (1995). Cognitive pragmatics. Shanghai: Shanghai Foreign Language Education Press.

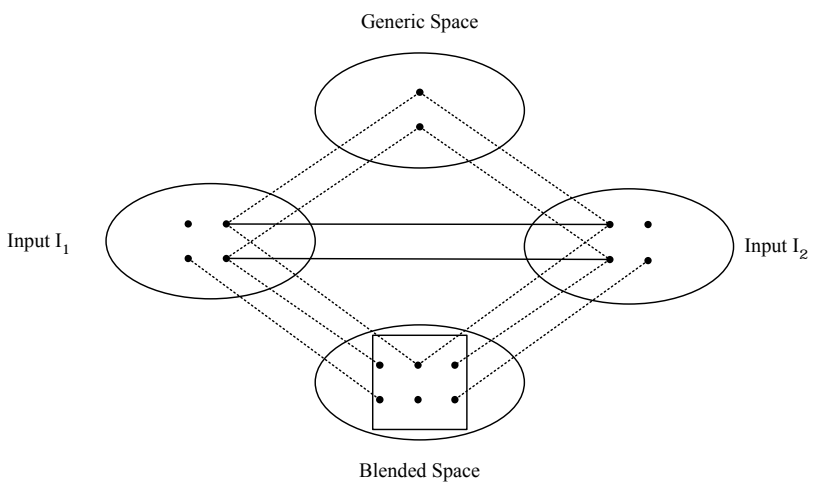

Figure 1.1

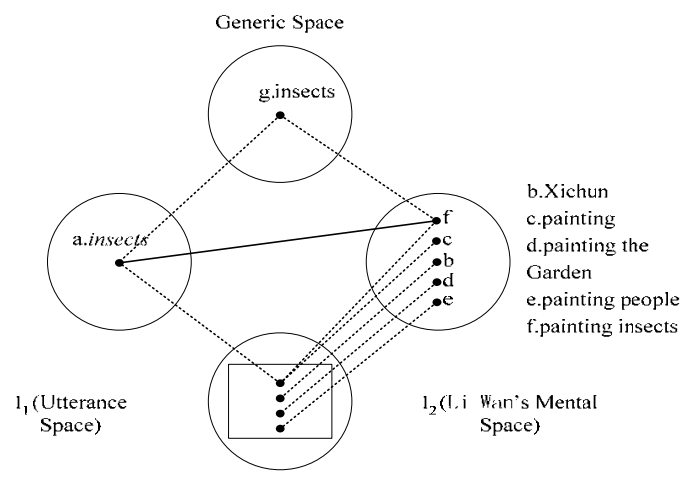

Blended Space

Figure 2.2

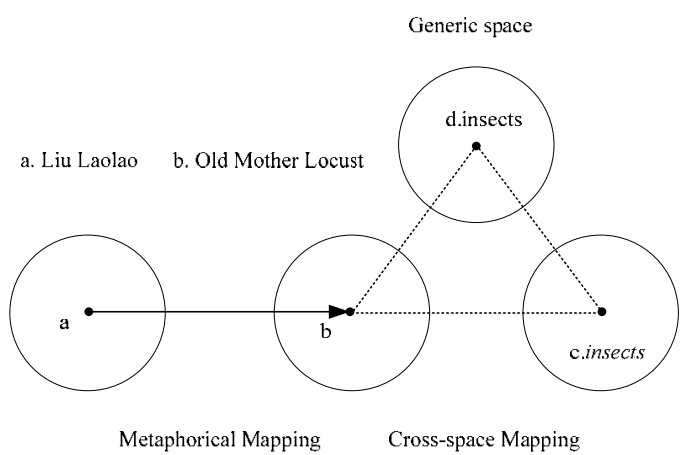

Figure 2.1

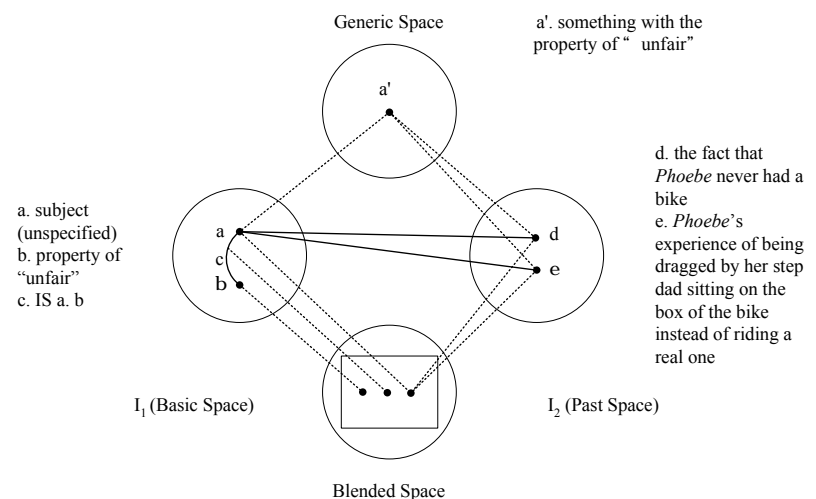

Figure 2.3 


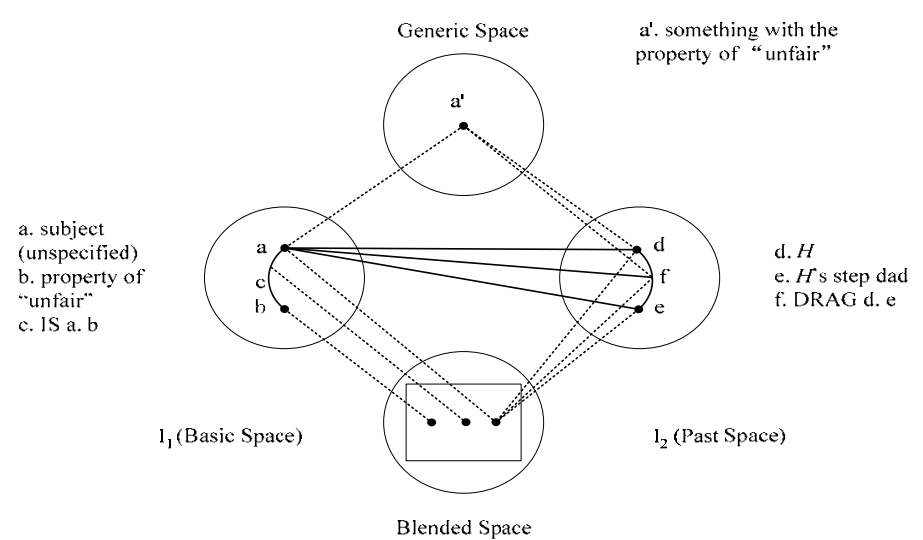

Figure 2.4

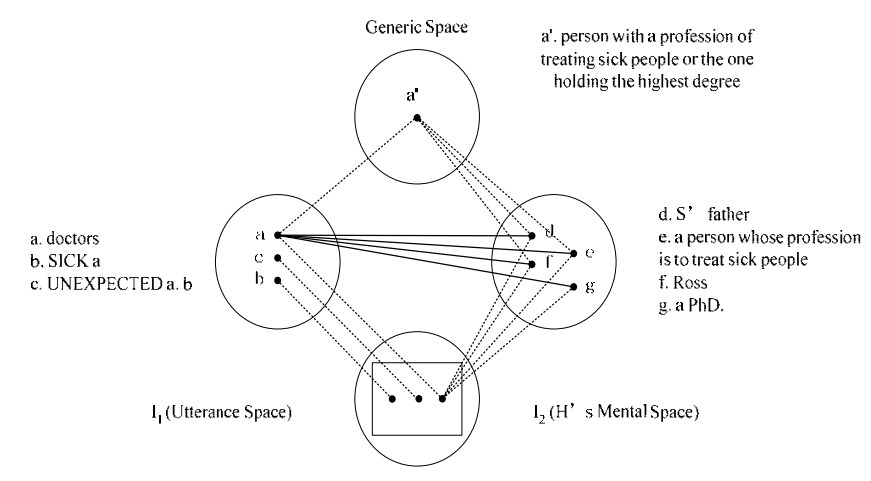

Blended Space

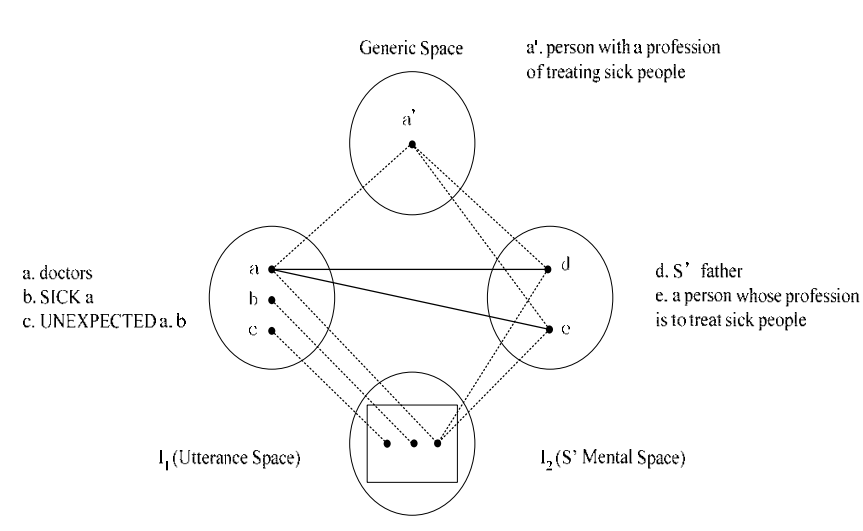

Blended Space

Figure 2.5

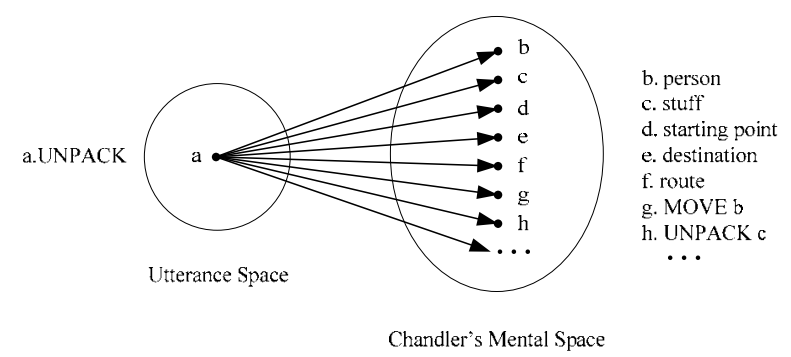

Figure 2.7

Figure 2.6

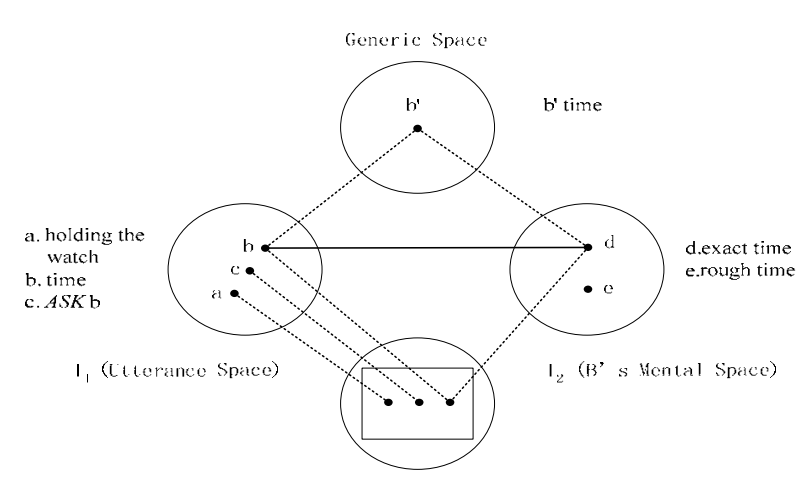

Blended Sprice

Figure 2.8

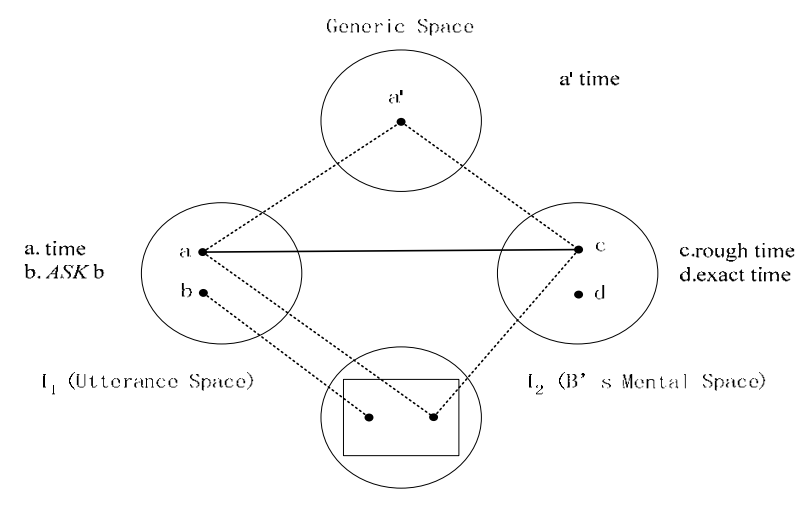

Blended Space

Figure 2.9 


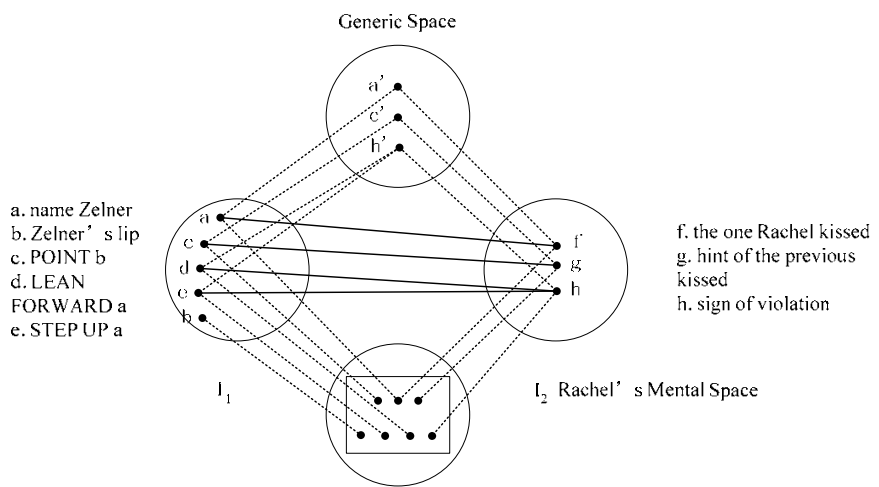

Blended Space

Figure 2.10

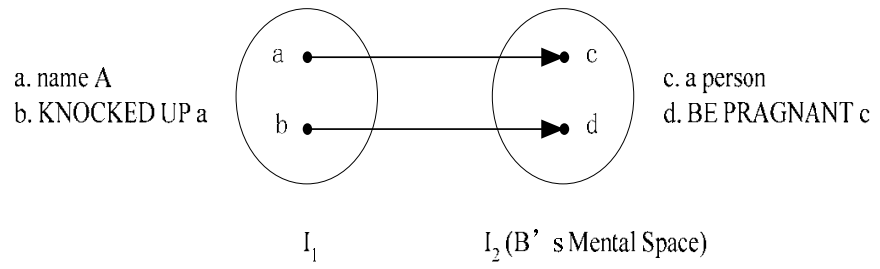

Figure 2.11

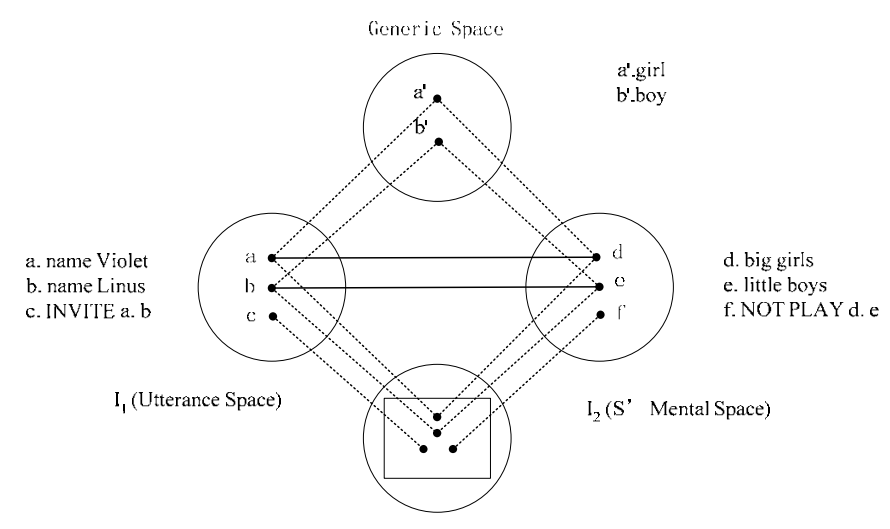

Blended Space

Figure 2.12

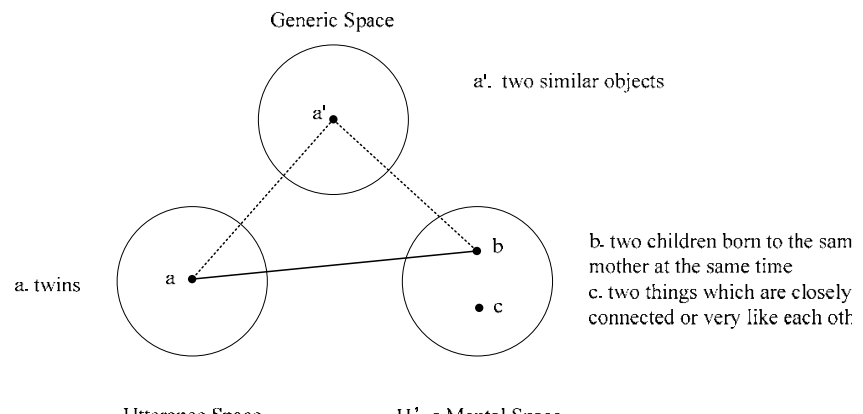

Utterance Space

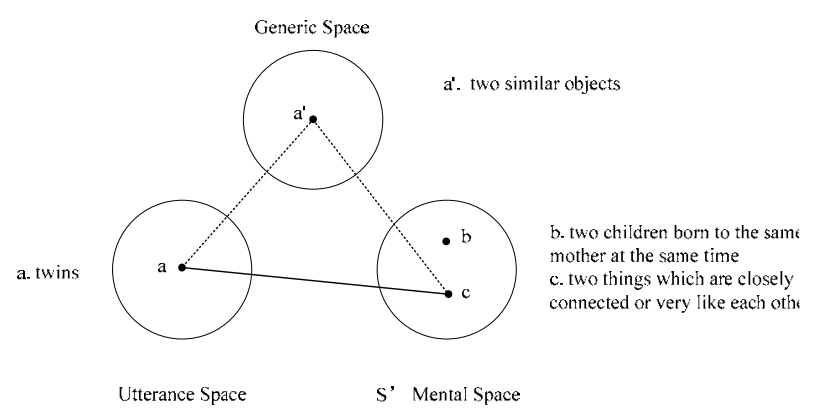

Figure 2.13

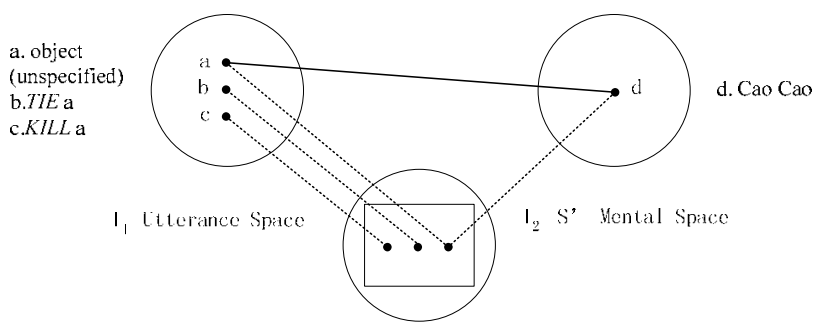

Blonded spece

Figure 2.15

Figure 2.14 